pathology into fifteen more or less arbitrary sections. These are intended to be flexible rather than rigid divisions and to help in planning future reviews so that the whole field can be covered regularly. This second volume comprises eighteen reviews falling into one or another of eight of these sections. Most of them come from North America but they include three contributions from Britain, one from the U.S.S.R. and one from Germany.

In a provocative opening chapter the doyen of plant pathology, Prof. E. C. Stakman, looks into the future of plant pathology by dwelling mainly in the past. It would seem that the plant pathologist must first understand normal plants and how they grow, and then accept as his prime obligation the production of completely healthy plants. This counsel of perfection is warmly advised in spite of the author's great appreciation of world food problems, his recognition that the greatest appeal of plant pathology to the public lies in its utility and his feeling that plant pathology must not lose agriculture or agriculture lose plant pathology.

The volume as a whole is an excellent one. Practically all the contributions serve admirably to meet the original aim for well-balanced interpretations of specialized sub. jects in language which those in other areas of plant pathology can understand and appreciate. Some of them provide very useful summaries of fringe subjects which might otherwise escape the potentially interested general reader if only because the literature is relatively scant or scattered or has not hitherto been looked at as a whole. They include ozone injury to plants, phanerogams as plant parasites in the New World tropics, and an account of plant toxins produced by plant pathogens and toxic only to the host of the pathogen. D. C. Graham's treatment of the taxonomy of soft rot bacteria pathogenic to plants is timely and helpful in that he combines the historical aspects with a summary of recent work and draws his own conclusions about the affinities of Erwinia and Pectobacterium which will stimulate discussion even if they do not gain full acceptance. It is also good to have an up-to-date and authoritative account of bacterial wilt used by Pserdomonas solanacearum, with special attention given to strains and dispersal.

On this occasion only one chapter is devoted to viruses and virus diseases, and this concerns the initiation and early stages of infection, particularly by mechanically transmitted viruses. In the one article on nematology the authors discuss the need for further knowledge about reproduction in parasitic nematodes as an aid in elucidating nematode systematics and the concept of biological species. There are five chapters in which soils come into the picture in one way or another. K. M. Domsch discusses some of the basic principles underlying the use of soil fungicides, and other reviews deal with the problem of soil fungistasis, some aspects of the effect on plants of the decomposition of plant residues in the soil, the role of mycorrhizae in root diseases and the influence of plant exudates on root-infecting fungi.

J. T. Martin assesses the importance of the epidermal cuticle as a barrier to invasion by micro-organisms and concludes that it plays only a secondary part compared with the effects of interaction between the metabolic processes of host and parasite within the cells. D. Wood. cock's study of microbial degradation of synthetic organic chemicals is probably intended mainly for the specialist. The remaining chapters concern the biology of hyperparasitism, host response to infection of xylem tissues, and the biochemical aspects of blackening and discoloration of plant tissues resulting from pathological and physiological disturbances.

All the reviews are fully documented, and in addition to author and subject indexes there are cumulative indexes to the chapter titles and contributors in the first two volumes.

\section{STRUCTURE AND FUNCTION OF THE RED BLOOD CELL}

The Red Blood Cell

A Comprehensive Treatise. Edited by Charles Bishop and Douglas M. Surgenor. Pp. xiv +566 . (New York: Academic Press, Inc.; London: Academic Press, Inc. (London), Ltd., 1964.) 121s. 6d.

$\mathrm{T}$

HERE have been several books on the red blood cell in the past five years, and this latest one claims to be the first written from the point of view of basic cell biology. It is also intended to be a complete treatise on the whole cell. To achieve this the authors decided to invite contributors who "are thoroughly competent in their area, critical of their own and other's work, and able to express themselves so that the neophyte can understand them". The result should therefore be comprehensive, discerning and explanatory.

The red cell is a relatively simple cell, devoid of nucleus (in most animals) and reproductive capacity and with functions limited to oxygen and carbon dioxide transport. The principal component of the cell, haemoglobin, without which man, according to Barcroft, would have achieved little activity not shown by a lobster, receives only brief consideration in two chapters which cover its association equilibria with oxygen, and its reduction. For a compound which has given so much insight into the importance of molecular structure and into the relationship of this structure to gene activity it is surprising to find that this subject and the haemoglobinopathies are omitted from the text. However, both these chapters are of high standard and give easily understandable accounts of difficult and fundamental aspects of this cell.

The metabolism of the cell is covered in a short chapter in which some of the glycolytic enzymes are briefly discussed, but there is no consideration given to the curious metabolic feature of this cell resulting from the large concentration of 2,3-diphosphoglycerate which it contains. Nor is there any mention of the enzyme pyruvic kinase which in the past few years has been revealed as an important link in the pathological physiology of the red cell. Indeed, this enzyme receives only the briefest mention in three places. Other chapters cover a variety of cell activities. The pentose phosphate pathway is admirably described by Dische, and Marks provides a comprehensive discussion of the significance, both physiological and pathological, of glucose 6-phosphate dehydrogenase. The red cell lipids are described in great detail and this chapter includes information on their fatty acid composition in the light of gas chromatographic analyses. There is also an excellent account of the chemistry of blood group substances by Watkins. Ion transport is covered in some detail by Passow; but the important topic of sugar permeability and that of other non-electrolytes is neglected. There are some useful chapters on the life-span of the red cell in health and disease, on the effects of certain vitamin deficiencies on red cell metabolism and on the important topic of red cell preservation, in which low-temperature storage in the frozen state is discussed. There is also a compendium of information in one chapter on red cell composition.

All in all, this is a useful book with plenty of references to the physiological activities of the red cell, but by and large it ignores cell pathology. It is incomplete in a number of important respects and tends to lack critical discussion in parts, but these are frequent inadequacies of multiple-author books, and one might best regard this book as a series of authoritative essays on certain selected aspects of red cell function.

T. A. J. Prankerd 